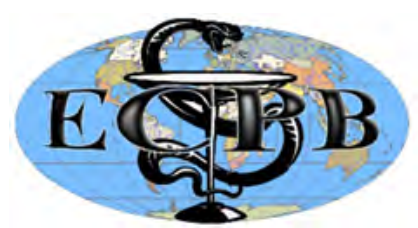

"ЕКСПЕРИМЕНТАЛЬНА ТА КЛІНІЧНА ФІЗІОЛОГІЯ І БІОХІМІЯ" "EXPERIMENTAL AND CLINICAL PHYSIOLOGY AND BIOCHEMISTRY" Науково-практичний журнал/Scientific-practical journal

Наукові статті / Research article ECPB 2018, 1(81): 27-32. https://doi.org/

\title{
Assessment of Nerve conduction in non-diabetic offspring of type 2 diabetic parents - a pilot study
}

\author{
K. TAMILSELVAN ${ }^{1}$, N. NIRMALA ${ }^{2}$, R. LATHA ${ }^{3}$, U. KARTHIKA PRIYADHARSHINI ${ }^{4}$, \\ S. NIVEATHA ${ }^{5}$, J. GODSON TITUS SAMUEL ${ }^{6}$ \\ ${ }^{1}$ Associate Professor, Department of Physiology, SVMCH \&RC, Puducherry \\ ${ }^{2}$ Professor \& HOD, Department of Physiology, SVMCH \&RC, Puducherry \\ ${ }^{3}$ Professor, Department of Physiology, SVMCH \&RC, Puducherry \\ ${ }^{4}$ Assistant Professor, Department of Physiology, SVMCH \&RC, Puducherry \\ ${ }^{5}$ II year post-graduate, Department of Physiology, SVMCH \&RC, Puducherry \\ ${ }^{6}$ III year M.B.B.S., Sri Venkateshwaraa Medical College Hospital and Research Centre \\ (SVMCH\&RC), Ariyur, Puducherry, India \\ E-mail: ktamilselvan10@gmail.com
}

Introduction. Diabetes is one of the leading causes of global morbidity and it is highly prevalent among the Asian and American Indians [20]. Type 2 Diabetes is an inherited metabolic condition characterised by the dysregulation of glucose homeostasis and its systemic sequels of blindness, kidney failure, heart attack, stroke and lower limb amputation which are attributable to its microvascular and macrovascular complications of impaired glycemic control. According to the WHO surveys 1.6 million deaths were attributed to diabetic cause in 2015 and diabetes is expected to be the seventh leading cause of death in 2030 [19]. Researches have made the observation that the development of the condition is more among those with a positive parental history, thus making the inference that type 2 diabetes in the vein of inherited disorders, is carried through generations as a genetic endowment with its expression being made more prominent with each generation $[11,12]$.

Type 2 Diabetes is a polygenic condition, precipitated by the interactions of genes, environment and other contributing factors. Recent medical researches on the pathogenesis of the diabetic state in the genetically susceptible population have made the controversial observations which are suggestive of altered systemic functions among non-diabetic offspring of diabetic parents even in their euglycemic state. The neurophysiological evaluation among this vulnerable population has revealed altered autonomic functions and prolonged latencies in the visual evoked potential (VEP) suggesting the involvement of the autonomic nervous system and the impaired visual processing even while being non-diabetic $[2,10]$. Biochemical and molecular studies in similar population have also revealed that the non-diabetic offspring of diabetic parents have microalbuminuria, the increased expression of oxidative stress marker, 8-hydroxydeoxy-guanosine (8-OHdG) and the decreased endothelium dependent vasodilation [7-9]. All these observations suggest that these changes in the offspring of diabetic parents are not always the ones that follow the impaired glycemic control characterised by elevated blood levels of glucose which lead to micro and macro vascular complications. As observations of autonomic dysfunction, retinopathic and nephropathic features are observable in the non-diabetic state of the euglycemic offspring of diabetic parents, this study has been designed to assess any change in the nerve conduction parameters as neuropathy is one among the important complications of microvasculopathies of diabetes.

(C) Tamilselvan K., Nirmala N., Latha R. et al., 2018 
Studies demonstrate that the sensory action potential is altered only after the involvement of large myelinated fibers and the motor nerve conduction velocity slowing is similar in both upper and lower limbs $[14,15]$. Therefore, this study has been designed to assess any change in the motor nerve conduction of the median nerve of non-diabetic offspring of diabetic parents.

Objectives. To assess any change in the nerve conduction among non-diabetic offspring of diabetic parents, it is necessary:

1) To evaluate the motor nerve conduction parameters as to motor distal latencies, amplitude and conduction velocity of the median nerve both in the control and study groups.

2) To infer the change in the motor nerve conduction parameters in the study group and compare the results between the groups.

Material and Methods. This cross sectional observational study was carried out in the research laboratory of the department of Physiology of Sri Venkateshwaraa Medical College, Hospital and Research Centre in Puducherry after obtaining the institutional ethical committee clearance. A total amount of 86 volunteers was recruited and 60 of them took part in the study. The subjects were right-handed, young adults and there were 30 volunteers in the study group and 30 in the control one. There was the equal gender distribution in each group. All the female volunteers were requested to report on the assessment during the menstrual phase as the ovarian hormones influence the neural functions during follicular and luteal phases.

Study groups. The age and BMI matched non-diabetic volunteers with the family history of type 2 DM (30 people - 15 males and 15 females).

The control group: Age and BMI matched non-diabetic volunteers without the family history of type 2 DM (30 people - 15 males and 15 females).

Inclusion criteria: Non-obese healthy volunteers with BMI in the range of $18.5-24.9 \mathrm{Kg} / \mathrm{m}^{2}$ within the age of $18-23$ years

Exclusion criteria: Volunteers with complaints of pain, tingling sensation, numbness, weakness of the upper limb, any other chronic disease like diabetes mellitus, thyroid disease, liver disease, hypertension, alcoholics, smokers, athletes and those with the parental history of hypertension were excluded from this study.

Methodology. Volunteers recruitment was based on the inclusion and exclusion criteria in the given study. The procedure was briefly explained and a written informed consent was obtained from all of them. After obtaining the consent, anthropometric measurements (height and weight) were taken to calculate Body Mass Index (BMI). The motor nerve conduction study of the median nerve was performed bilaterally - in the research lab using NEUROSTIM, MEDICAID SYSTEMS and surface electrodes. The recording (active) electrode was placed close to the motor point of Abductor Pollicis Brevis muscle and the reference electrode was placed $3 \mathrm{~cm}$ distal to the active electrode at the first metacarpophalangeal joint. The ground electrode was placed between the stimulating and recording electrodes. With the help of stimulating electrodes the supramaximal stimulation was given first at the wrist then at elbow to obtain Compound Muscle Action Potential (CMAP). The distance between the wrist and elbow was measured [13]. Motor Distal Latency (MDL), Amplitude (Amp) and Conduction Velocity (CV) were measured. The procedure was carried out at the ambient room temperature ranging from $23^{\circ} \mathrm{C}$ to $25^{\circ} \mathrm{C}$ to avoid the effect of temperature on the nerve conduction.

Statistical analysis. Data were presented as Mean \pm Standard Deviation. The analysis was done by using SPSS 17. Students unpaired ' $t$ ' test was used to compare the parameters between the two groups. P value $<0.05$ is considered statistically significant.

Results. The above table (Table 1) depicts the gender distribution, mean and standard deviation of age and BMI of the participants in the study and control groups. 
Table 1

Comparison of Anthropometric measurements between study and control groups

\begin{tabular}{|c|c|c|c|}
\hline Parameters & Study group & Control group & $\boldsymbol{P}$ value \\
\hline No of participants & 30 & 30 & - \\
\hline Male/Female & $15 / 15$ & $15 / 15$ & 0.932 \\
\hline Age (in years) & $18.17 \pm 1.15$ & $18.29 \pm 0.8$ & 0.5153 \\
\hline BMI $\left(\mathrm{Kg} / \mathrm{m}^{2}\right)$ & $20.15 \pm 1.4$ & $21.37 \pm 1.23$ & - \\
\hline
\end{tabular}

There is no difference as to the age and BMI between the groups and there was equal gender distribution in each group.

Table 2

Comparison of the median motor nerve conduction parameters between Right (dominant) hands of the study and control groups

\begin{tabular}{|c|c|c|c|}
\hline $\begin{array}{c}\text { Motor nerve conduction } \\
\text { parameters of Right hand }\end{array}$ & Study group & Control group & $\boldsymbol{P}$ value \\
\hline Latency $(\mathrm{ms})$ & $3.13 \pm 0.81$ & $2.59 \pm 1.4$ & 0.0726 \\
\hline Amplitude $(\mathrm{mV})$ & $8.94 \pm 1.29$ & $9.58 \pm 1.42$ & 0.0728 \\
\hline Conduction velocity $(\mathrm{m} / \mathrm{s})$ & $56.19 \pm 2.34$ & $57.51 \pm 3.08$ & 0.0667 \\
\hline
\end{tabular}

The above table (Table 2) shows the comparison between latency, amplitude and conduction velocity of the motor component of the right median nerve between the study and control groups. There was no significant difference in any of the parameters as the $\mathrm{P}$ value is more than 0.05 .

Table 3

Comparison of the median motor nerve conduction parameters between Left (nondominant) hands of study and control groups

\begin{tabular}{|c|c|c|c|}
\hline $\begin{array}{c}\text { Motor nerve conduction } \\
\text { parameters }\end{array}$ & Study group & Control group & $\boldsymbol{P}$ value \\
\hline Latency $(\mathrm{ms})$ & $3.69 \pm 1.21$ & $2.98 \pm 1.79$ & 0.0771 \\
\hline Amplitude $(\mathrm{mV})$ & $7.26 \pm 2.39$ & $8.24 \pm 1.95$ & 0.0871 \\
\hline Conduction velocity $(\mathrm{m} / \mathrm{s})$ & $57.62 \pm 1.76$ & $58.49 \pm 2.07$ & 0.0847 \\
\hline
\end{tabular}

The above table (Table 3) shows the comparison between latency, amplitude and conduction velocity of the motor component of the left median nerve between the study and control groups. There was no significant difference in any of the parameters as the $P$ value is more than 0.05 .

Discussion. Type 2 Diabetes mellitus is a group of metabolic diseases characterized by dysregulated glucose homeostasis by defects in insulin secretion, insulin action or both leading to hyperglycemia which in its chronicity can lead to long-term damage, dysfunction and failure of various organs, especially the eyes, kidneys, nerves, heart and blood vessels [1]. The specific susceptibility of these structures to diabetic complication lies in the fact that the capillary endothelial cells in the retina, mesangial cells in the renal glomerulus and neurons and Schwann cells in peripheral nerves are vulnerable to hyperglycaemia as they do not posses efficient mechanisms of down regulating glucose entry in the hyperglycemic environment to maintain a constant intracellular glucose concentration unlike the other tissues of the body [3].

The pathogeneisis of diabetic outcomes are consequent to the chronic hyperglycaemia, as the dysregulated entry of the glucose into the vulnerable tissues leads to microvascular complications by decreasing the antioxidants via polyol pathway, compromising endothelial functions by modifying intracel- 
lular proteins and the extracellular matrix modification by advanced glycation end products (AGE products) that are formed and diffused out of these cells, cellular derangement by the activation of protein kinase $\mathrm{C}$ pathway that upregulates the vasoconstrictor production and downregulates the vasodilator production and by the increased expression of transforming growth factor-1 and plasminogen activator inhibitor- 1 by the enhanced hexosamine pathway activity. Ultimately, all these mechanisms lead to microangiopathy that declines the functions of vulnerable tissues [3]. Therefore, the mechanism of diabetic complication is theoretically secondary to hyperglycemia. But medical literature has reported recently about controversial findings of changes in the organ functions like the significant albumin excretion, elevated serum levels of oxidative stress markers, the impaired sympathovagal balance and prolongation of VEP latencies in the normoglycemic (non-diabetic) offspring of diabetic parents. Such significant observations of systemic derangement among the non-diabetic offspring of diabetic parents who are genetically susceptible to develop the condition of diabetes puts to doubt the concept of hyperglycemia as the forerunner of systemic derangement and impaired glycemic control leading to microvasculopathy that precipitates the impairment in the neural, retinal and nephron functions. Therefore, it could be hypothesised that mechanisms beyond hyperglycemia making systemic functions worse should play a role in such conditions. The probable mechanism could be the role of epigenetic modulation of the expression of the diabetic phenotype.

Retinopathy is reported to be more important among those with neuropathy in diabetes [16]. As such a feature of the impaired activity along the visual pathway has been reported among the non-diabetic offspring of diabetic parents, this study has been planned to assess any change in the nerve conduction in the similar population. Nerve damage and its derangement can be determined by nerve conduction studies. The motor nerve conduction studies analyse specific parameters like latency, amplitude and conduction velocity. The latency of the compound muscle action potential (CMAP) indicates the speed of conduction in nerves whereas the amplitude of CMAP refers to the density of nerve fibers and the muscle mass is activated by the stimulation of the motor nerve [4].

As it is known earlier, neuropathy of diabetes is due to chronic hyperglycemia which causes the formation and deposition of AGE in the stromal collagens, axoplasms of nerve fibers, Schwann cells and endoneurial vessels which ultimately delay nerve conduction velocity, reduce nerve $\mathrm{Na}, \mathrm{K}$-ATPase activity and reduce the myelinated nerve fibers size [17]. On the contrary, the association of neuropathy with $\mathrm{Na}, \mathrm{K}$-ATPase gene mutation among diabetics has also been reported that brings to light the role of gene in disease amplification [18]. As type 2 diabetes is a polygenic condition involving more than a 100 gene loci approximately, the onset and progress of the condition depends on the gene expression to bring the diabetic phenotype [6]. Therefore, a probable explanation to the observation of altered functions even in the euglycemic state of non-diabetic offspring of diabetic parents could be due to the epigenetic mechanism of interaction between these diabetic gene with various regulatory gene and the environment.

As the delay in nerve conduction latencies precedes clinical neuropathy and the involvement of the motor component of the median nerve has also been reported among asymptomatic diabetics with subclinical neuropathy, this study has been designed to evaluate the nerve conduction parameters of the motor component of the median nerve as it is easily accessible for the assessment [5].

In our pilot attempt we found no significant change in the motor nerve conduction which could be due to the non-involvement of the neural system in their non-diabetic state. But it would be best to make such a conclusion only by evaluating both motor and sensory nerves in both upper and lower limbs, as features of neural involvement like changes in VEP have been observed in similar population. 
Conclusion. In our pilot study we found no significant change in the nerve conduction velocity of the motor component of the median nerve among the non-diabetic offspring of diabetic parents though an altered autonomic functions and changes in VEP have been reported in similar population. The observation of our study is the evidence to the rationale of the neural involvement as being secondary to the formation and deposition of advanced glycation end-products as a result of hyperglycemia. Since the study population was non-diabetics who are genetically susceptible to develop the condition, the absence of change in the nerve conduction parameters could be due to their intact glycemic regulation. However, the hypothesis of non-involvement of neural function in them could be affirmed only with the complete evaluation of motor and sensory components of all peripheral nerves. Therefore, future researches are aimed at evaluating this hypothesis as a large population study should be designed and the correlation between the parental contribution and its heredity has to be taken into consideration.

Authors state no conflicts of interest.

\section{REFERENCES}

1. American Diabetes Association. Diagnosis and classification of diabetes mellitus. Diabetes care. 2004 Jan 1;27 (suppl 1). S.5-10. 2. Anitha Achuthan, Janani Ramesh. Pattern Visual Evoked Potential in Non-Diabetic offsprings of Type II Diabetes. JMR 2015; 1(3):83-86. 3. Brownlee $M$. The pathobiology of diabetic complications. Diabetes. 2005 June 1;54(6):1615-25. 4. Daube $J R$, Rubin DI. Nerve conduction studies. //Aminoff's Electrodiagnosis in Clinical Neurology. 6th ed. China: Elsevier Saunders Inc., 2012: 2906. 5. Garg R, Kumar A, Dhar U. A Study of Median Nerve Conduction Velocity in Diabetes Mellitus Type 2 in Neurologically Asymptomatic Patients. International Journal of Health Science and Research. 2013; 3(5):42-9. 6. Gaulton KJ. Mechanisms of type 2 diabetes risk loci. Current diabetes reports. 2017. Sep 1;17(9):72. 7. Goldfine AB, Beckman JA, Betensky RA, Devlin H, Hurley S, Varo $N$ et al. Family history of diabetes is a major determinant of endothelial function. Journal of the American College of Cardiology. 2006. June 20;47(12):2456-61. 8. Gruden G, Cavallo-Perin P, Olivetti C, Repetti E, Sivieri R, Bruno A, Pagano G. Albumin excretion rate levels in non-diabetic offspring of NIDDM patients with and without nephropathy. Diabetologia. 1995. Oct 1;38(10):1218-22. 9. Hasan M, Mohieldein AH, Almutairi FR. Comparative study of serum 8-hydroxydeoxy-guanosine levels among healthy offspring of diabetic and non-diabetic parents. International Journal of Health Sciences. 2017. Jul;11(3):33. 10. Khatri Anshu, Aggarwal Tanu, Changotra Parshant. Heart Rate Variability In Non Diabetic Offsprings Of Type 2 Diabetic Patients. Journal of Advance Researches in Biological Sciences, 2013, Vol. 5 (2). P. 139-43. 11. Klein BE, Klein R, Moss SE, Cruickshanks KJ. Parental history of diabetes in a population based study. Diabetes Care. 1996; 19 (8): 827-30. 12. Marianne AB van der Sande, Gijs EL Walraven, Paul JM Milligan, Winston AS Banya, Sana M Ceesay, Ousman A Nyan, Keith PWJ McAdam. Family history: an opportunity for early interventions and improved control of hypertension, obesity and diabetes. Bulletin of the World Health Organization, 2001. 79 (4):321-8. 13. Misra UK, Kalita J. Nerve conduction study. Clinical Neurophysiology. New Delhi, Elsevier; 1999: 29-30. 14. Refaat R, Abdelhameed AM, Elbarbary NS, El-Hilaly RA. Evaluation of median nerve in children with type1 diabetes using ultrasonographic imaging and electrophysiology. The Egyptian Journal of Radiology and Nuclear Medicine. 2013. September 30;44(3):563-72. 15. Said G. Diabetic neuropathy-a review. Nature clinical practice Neurology. 2007. June 1;3(6):331-40. 16. Sharma $V K$, Joshi $M V$, Vishnoi $A A$. Interrelation of retinopathy with peripheral neuropathy in diabetes mellitus. Journal of Clinical Ophthalmology and Research. 2016. May 1;4(2):83. 17. Sugimoto $K$, Yasujima M, Yagihashi S. Role of advanced glycation end products in diabetic neuropathy. Current pharmaceutical design. 2008. April 1;14(10):953-61. 18. Vague P, Dufayet D, Coste T, Moriscot C, Jannot MF, Raccah D. Association of diabetic neuropathy with Na/K ATPase gene polymorphism. Diabetologia. 1997. April 1;40(5):506-11. 19. World Health Organization. Diabetes, Factsheet Internet. Geneva: World Health Organization. 2017. November. Available from http:// www.who.int/mediacentre/factsheets/fs312/en/. 20. Wy So, Mcy Ng, Sc Lee, T. Sanke, H. K. Lee, J.C.N Chan. Genetics of type 2 diabetes mellitus. HKMKJ. 2000. 6:69-76. 


\title{
RESEARCH ARTICLES
}

\section{Assessment of Nerve conduction in non-diabetic offspring of type 2 diabetic parents - a pilot study}

\author{
K. TAMILSELVAN ${ }^{1}$, N. NIRMALA ${ }^{2}$, R. LATHA ${ }^{3}$, U. KARTHIKA \\ PRIYADHARSHINI ${ }^{4}$, S. NIVEATHA ${ }^{5}$, J. GODSON TITUS SAMUEL ${ }^{6}$ \\ 1 Associate Professor, Department of Physiology, SVMCH \&RC, Puducherry \\ 2 Professor \& HOD, Department of Physiology, SVMCH \&RC, Puducherry \\ 3 Professor, Department of Physiology, SVMCH \&RC, Puducherry \\ 4Assistant Professor, Department of Physiology, SVMCH \&RC, Puducherry \\ 5 II year post-graduate, Department of Physiology, SVMCH \&RC, Puducherry \\ 6 III year M.B.B.S., Sri Venkateshwaraa Medical College Hospital and Research Centre \\ (SVMCH\&RC), Ariyur, Puducherry. \\ E-mail: ktamilselvan10@gmail.com
}

Introduction. Diabetes is a leading cause of global morbidity and mortality. As genetic inheritance is involved in the pathogenesis of the disease, polymorphism of various genes and genetic mutations could be implicated in the phenotype of the disease manifestation. Recently studies on inheritance of type 2 diabetes mellitus have revealed the observation that the offspring of diabetic parents have forewarning findings of altered neural and autonomic functions even in their non-diabetic state. Therefore, this study has been designed to assess any change in nerve conduction parameters of the motor component of the median nerve in the same population.

Objectives. To assess the median motor nerve conduction parameters in non-diabetic offspring of type 2 diabetic and non-diabetic parents and infer the changes in the study population by comparing the groups mentioned above.

Material and Methods. The Nerve conduction study of the median nerve (motor component) was carried out on both hands of 60 non-diabetic volunteers aged between 18-25 (30 offspring of type 2 diabetic parents and 30 offspring of non-diabetic parents with equal number by gender in each group) in normal BMI range.

Results. The comparison between the groups revealed no significant difference in latency, amplitude and conduction velocity in the motor component of the median nerve.

Conclusion. In our study we have observed that there is no significant difference in the motor nerve latencies between the groups. Unlike the observations of altered visually evoked potentials and autonomic impairment in similar population by other studies, the observation of non-involvement of the somatic nerve could be discussed as a sequel to glycation of neural structures that could impair the neuronal activity.

Key words: motor nerve conduction, offspring of Type 2 diabetic parents. 